\title{
Receptores del hospedero implicados en la invasión del merozoito de Plasmodium falciparum: revisión
}

\author{
Jessica S Molina-Franky', Alida M Gómez-Rodríguez¹, César Reyes², David Fernando Plaza ${ }^{3}$
}

\begin{abstract}
RESUMEN
Introducción. La malaria es un problema de salud pública a nivel mundial y es causada por 5 especies de parásitos apicomplejos del género Plasmodium. La invasión exitosa de los merozoítos al glóbulo rojo es una etapa fundamental en el ciclo de vida del parásito, el cual usa un variado repertorio de ligandos que interactúan de forma específica con receptores presentes en la membrana del glóbulo rojo.

Objetivo. Revisar las características moleculares y estructurales de los receptores expresados en la superficie de los glóbulos rojos, implicados en el proceso de invasión del merozoito de Plasmodium falciparum.

Método. Revisión descriptiva sobre las características moleculares y estructurales de los receptores de la superficie del glóbulo rojo, los cuales juegan un papel fundamental durante la invasión del merozoíto de Plasmodium falciparum. Esta revisión empezó por la búsqueda de literatura publicada hasta el año 2019 en bases de datos electrónicas, especializadas en la divulgación de investigación biomédica. Se encontraron 127 documentos, de los cuales se seleccionaron 111 y se excluyeron 33 por no cumplir los criterios de inclusión; en total, se analizaron 78 referencias.

Conclusión. En esta revisión se resumieron las características moleculares y estructurales de los receptores presentes en el glóbulo rojo importantes en el proceso de invasión del merozoito de $P$. falciparum. También, se resaltó la importancia de elucidar las diferentes vías de invasión del parásito y así, poder desarrollar alternativas profilácticas o terapéuticas que conduzcan a mitigar o eliminar la malaria.
\end{abstract}

Palabras clave: malaria, Plasmodium falciparum, eritrocitos, merozoito, proteínas de membrana, receptor.

\footnotetext{
${ }^{1}$ Universidad de Boyacá, Tunja, Colombia

2 Universidad del Rosario, Bogotá, Colombia

${ }^{3}$ Fundación Instituto de Inmunología de Colombia, Bogotá, Colombia
}

Correspondencia: Jessica S Molina-Franky. Dirección Carrera 2a este №64-169. Tunja (Boyacá), Colombia. Celular: 3227354567

Correo electronico: jesmolina@uniboyaca.edu.co

Citar este artículo así:

Molina-Franky JS, Gómez-Rodríguez AM, Reyes C, Plaza DF. Receptores del hospedero implicados en la invasión del merozoito de Plasmodium falciparum: revisión. Revista Investig Salud Univ Boyacá. 2019;6(2): 158-181. doi: https://doi.org/10.24267/23897325.348 
Host receptors involved in the invasion of Plasmodium falciparum merozoite: Review

\begin{abstract}
Introduction. Malaria is a public health problem worldwide. It is caused by 5 species of the Apicomplexa genus Plasmodium. The successful invasion of the erythrocyte by Plasmodium merozoites is a critical stage in the life cycle of the parasite, which uses a broad repertoire of ligands that interact in a specific way with receptors expressed on the membrane of the erythrocyte.

Objective. To review the molecular and structural characteristics of the receptors expressed on the erythrocyte surface, involved in the process of merozoite invasion by Plasmodium falciparum.

Method. Here, we descriptively review of the molecular and structural characteristics of the red blood cell surface receptors, which play a key role during the invasion of Plasmodum falciparum merozoite. To this purpose, we searched the literature published until 2019 in electronic databases specialized in biomedical research. 127 documents were found, of these, 111 were selected, 33 were excluded and 78 references were analyzed.

Conclusion. In this review, the molecular and structural characteristics of the receptors expressed on the erythrocytes and important in the process of invasion of $P$. falciparum merozoites were discussed. With this, we highlight the importance of elucidating the different invasion pathways the parasite, in order to develop prophylactic or therapeutic alternatives that could lead to mitigate or eliminate malaria.
\end{abstract}

Key words: malaria, Plasmodium falciparum, erythrocytes, merozoite, membrane protein, receptor. 


\title{
Receptores do hospedeiro envolvidos na invasão do merozoíto de Plasmodium falciparum: revisão
}

\begin{abstract}
RESUMO
Introdução. A malária é um problema de saúde pública a nível mundial, é causada por 5 espécies de parasitos do Filo Apicomplexa, do gênero Plasmodium. A invasão bem-sucedida de merozoítos nas hemácias, é uma etapa fundamental no ciclo de vida do parasita, que usa um repertório variado de ligandos que interatuam especificamente com receptores presentes na membrana dos glóbulos vermelhos.
\end{abstract}

Objetivo. Revisão descritiva das características moleculares e estruturais dos receptores da superfície dos glóbulos vermelhos, que desempenham um papel fundamental durante a invasão do merozoíto de Plasmodium falciparum.

Método. Revisão descritiva das características moleculares e estruturais dos receptores da superfície dos glóbulos vermelhos, que desempenham um papel fundamental durante a invasão do merozoíto de Plasmodium falciparum. Esta revisão foi baseada na pesquisa de literatura publicada até 2019 nas bases de dados eletrônicas especializadas na divulgação de pesquisas biomédicas. Foram encontrados 127 documentos, dos quais 111 foram selecionados e 33 foram excluídos por não apresentarem os critérios de inclusão, analisando um total de 78 referências.

Conclusão. Nesta revisão, foram resumidas as características moleculares e estruturais dos receptores presentes nos glóbulos vermelhos, importantes no processo de invasão do merozoíto de P. falciparum. Também foi destacada a importância de elucidar as diferentes vias de invasão do parasita, a fim de desenvolver alternativas profiláticas ou terapêuticas que levem a mitigar ou eliminar a malária.

Palavras-chaves: Malária, Plasmodium falciparum, glóbulos vermelhos, merozoíto, proteínas de membrana, receptor. 


\section{INTRODUCCIÓN}

La malaria representa un problema de salud pública a nivel mundial. En el año 2017 se registraron 219 millones de casos y 451.000 muertes (1). Esta enfermedad es causada por cinco especies del género Plasmodium: Plasmodium falciparum, Plasmodium vivax, Plasmodium ovale, Plasmodium malaria y Plasmodium knowlesi, siendo P. falciparum el principal causante de la morbimortalidad (2).

El ciclo de vida de $P$. falciparum empieza cuando un mosquito Anopheles hembra, infectado, inyecta en la piel del hospedero de 100 a 1000 esporozoítos (spz), los cuales se mueven en la dermis hasta ser capturados por un capilar. Esto le permite al spz viajar a través del torrente sanguíneo hasta el hígado e invadir a los hepatocitos presentes. La ruptura de los hepatocitos libera merozoitos (mrz) que reingresan al torrente sanguíneo, donde invaden a los glóbulos rojos (GR); allí, en el citoplasma de estos, forman una vacuola parasitófora, en la cual maduran pasando por los estadios de anillo, trofozoíto y esquizonte, hasta culminar en la ruptura del GR y la liberación de nuevos mrz. Cada mrz liberado invade una nueva célula eritroide, con lo cual se produce lisis en masa de células hospederas y, con esto, los síntomas de la enfermedad (fiebre, anemia) (Figura 1A) (3-5).
Los eventos moleculares involucrados en la interacción del mrz con el GR, están distribuidos en las etapas: contacto inicial, reorientación apical, formación de la unión estrecha e invasión activa. El contacto inicial y la leve deformación de la membrana del eritrocito, están determinados por la interacción entre el complejo de proteínas de superficie del merozoito (MSP-1, por sus siglas en inglés) y los receptores banda 3 y glicoforina $A$ (GPA); adicionalmente, la reorientación apical del mrz y la fuerte deformación de la mebrana del $\mathrm{GR}$, se producen gracias a la liberación de los ligandos pertenecientes a las familias de proteínas de unión a eritrocitos (EBL) o de las proteínas homólogas de unión a reticulocito de $P$. falciparum (PfRh) y finalmente, la unión estrecha e invasión activa, se producen por la unión de las proteínas AMA-1 y RON al GR $(6,7)$.

Este proceso demuestra que la invasión exitosa, mediada por la interacción específica entre las proteínas expresadas por los mrz y los receptores presentes en la superficie de los GR, representa un paso esencial en el complejo ciclo de vida de $P$. falciparum (8). Lo anterior, resalta la necesidad de identificar y caracterizar las interacciones moleculares tipo receptor-ligando, así como los mecanismos de adhesión e invasión del mrz al hospedero, los cuales ayudarán a comprender la biología del parásito y servirán como base fundamental en el desarrollo de alternativas profilácticas o terapéuticas que conduzcan a mitigar o eliminar la enfermedad. 
Así, esta revisión compila y resume las características moleculares y estructurales de los receptores expresados en la superficie de los GR implicados en el proceso de invasión del mrz de $P$. falciparum.

\section{METODOLOGíA}

Se llevó a cabo una revisión descriptiva sobre los receptores expresados en la superficie de los GR implicados en el proceso de invasión de $P$. falciparum. La búsqueda de la literatura relacionada con el tema de estudio se realizó a partir de artículos y guías de referencia mundial de la Organización Mundial de la Salud (OMS) para esta entidad, publicados en las bases de datos electrónicas PubMed, Science Direct, MedLine y Embase.

Las palabras clave se seleccionaron con base en el descriptor Medical Subject Headings (MeSH) en idioma inglés: malaria, Plasmodium falciparum, erythrocytes, invasion, membrane protein y receptor.

Fueron escogidos todos los artículos y guías disponibles, publicados hasta el año 2019 y escritos en idioma inglés. Se encontraron 127 documentos entre artículos y guías, de los cuales se seleccionaron 111 por título y resumen; de estos se excluyeron 33 por no presentar las propiedades estructurales y funcionales de las proteínas ni su relevancia en el proceso de invasión de los mrz. En total, se analizaron 78 referencias.
Finalmente, de las 78 referencias seleccionadas, se compilaron y resumieron las características moleculares y estructurales de los receptores expresados en la superficie de los $G R$, implicados en el proceso de invasión del mrz de $P$. falciparum.

\section{RESULTADOS}

\section{Proceso de invasión del merozoíto al glóbulo rojo}

La invasión durante la etapa sanguínea del parásito comienza con la interacción entre proteínas del mrz y receptores presentes en la superficie de los GR. Los mrz tienen en la región apical organelos denominados roptrias y micronemas que, al primer contacto con la superficie de células eritrocíticas, liberan una serie de proteínas que median los pasos finales en el proceso de invasión a la célula hospedera (Figura 1B) $(9,10)$.

El proceso de invasión del mrz al GR, toma $\sim 20$ segundos e incluye diferentes estadios (contacto inicial, reorientación apical, formación de la unión estrecha e invasión activa) (11) (Figura 1C). El contacto inicial del mrz causa una leve deformación en la superficie del GR mediada por interacciones de baja afinidad entre MSP-1,6/7 y la proteína de superficie del merozoíto de unión a duffy (MSPDBL), que se unen a los receptores de banda 3 y glicoforina A (GPA) presentes en la superficie del GR (12-14). 
Esta etapa es seguida por la reorientación apical y una fuerte deformación de la membrana del $\mathrm{GR}$, inducidas por la unión de cualquiera de las proteínas EBL (EBA-175, EBA-140/BAEBL, EBA-181/JESEBL, EBL-1 Y MAEBL) (15), o de las proteínas PfRH (PfRH1, PfRH2a, PfRH4) $(10,16,17)$ $(10,16,17)$. Esto depende de las características de los receptores y la presencia de anticuerpos preformados por infecciones previas, para luego permitir la unión de PfRH5 al receptor de basigina (BSG), desencadenando la liberación de las proteínas de las roptrias, proceso mediado por el flujo de $\mathrm{Ca}^{2+}$ en la interfaz parásito-huésped (6).

Posteriormente, se produce una unión estrecha a través de la inserción del complejo proteico conformado por la proteína de cuello de roptria (RON) y el antígeno de membrana apical- 1 (AMA-1) en la membrana del GR. La fuerza de penetración del parásito es generada por el motor actina-miosina, conduciendo al mrz a través de la membrana celular del hospedero al interior de un compartimento denominado vacuola parasitófora, creado por la secreción de las proteínas de las roptrias (Figura1C) $(7,18)$.

El conocimiento de los receptores en los GR que sirven como ruta de invasión de $P$. falciparum es muy limitado; hasta la fecha, se han caracterizado más de 50 ligandos y solo 9 receptores en GR maduros, incluyendo a la GPA, glicoforina B (GBP), glicoforina C (GPC), BSG, receptor del complemento 1 (CR1), semaforina-7A (SEMA7A), banda 3, heparina y los receptores hipotéticos KX, $Z, Y$ y W, determinados de acuerdo con el perfil de sensibilidad enzimática (Figura 1D) (19-21).

\section{Receptores que interactúan con proteínas de los micronemas de P. falciparum}

\section{Glicoforina A}

GPA es una proteína transmembrana que junto a banda 3 es la más abundante en la membrana de los GR ( $1 \times 10^{6}$ copias por célula) (22). Está conformada por 150 aminoácidos (72 en el dominio extracelular, seguido de 23 en el dominio transmembrana y 36 en el dominio intracelular) y 16 $\mathrm{N}$-oligosacáridos decorados con ácido siálico (23) (Figura 2A).

Su función principal es la determinación antigénica para los grupos sanguíneos MN y Ss; así mismo, está involucrada en la interacción entre los GR y el endotelio vascular (24).

GPA fue el primer receptor en el GR identificado para un ligando de invasión de $P$. falciparum, el antígeno de unión a eritrocito-175 (EBA-175). Esta interacción es resistente al tratamiento de los GRs con quimiotripsina (25) y es mediada por la región II rica en cisteínas de EBA-175, la cual está conformada por los dominios F1 y F2 $(26,27)$. 
Figura 1. A. Ciclo de vida de P. falciparum B. Localización de las proteínas expresadas por el merozoíto de P. falciparum C. Etapas de invasión del merozoíto al glóbulo rojo D. Receptores presentes en la membrana del glóbulo rojo importantes para la unión de proteínas de P. falciparum

A.

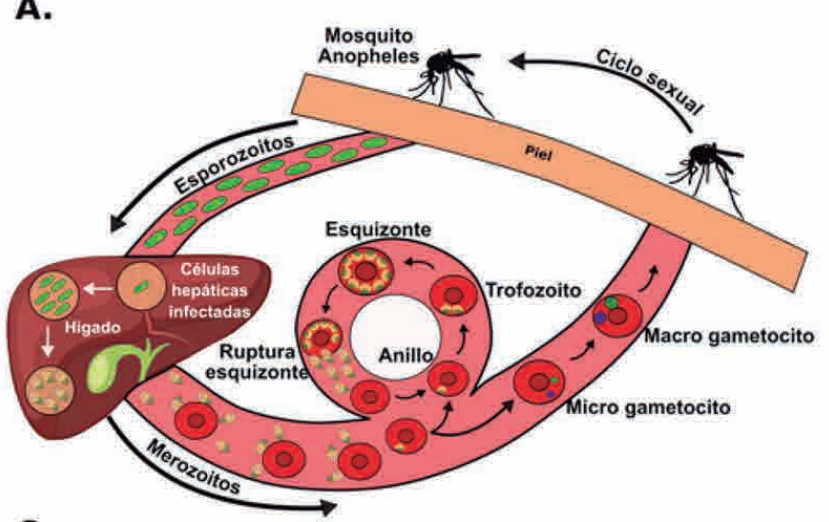

c.

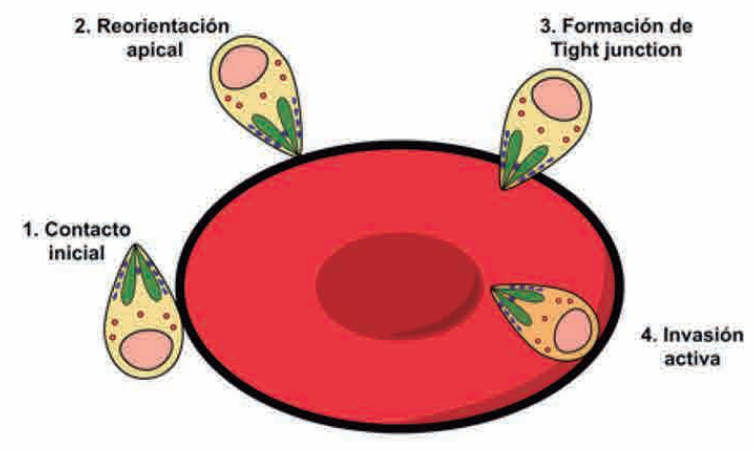

B.
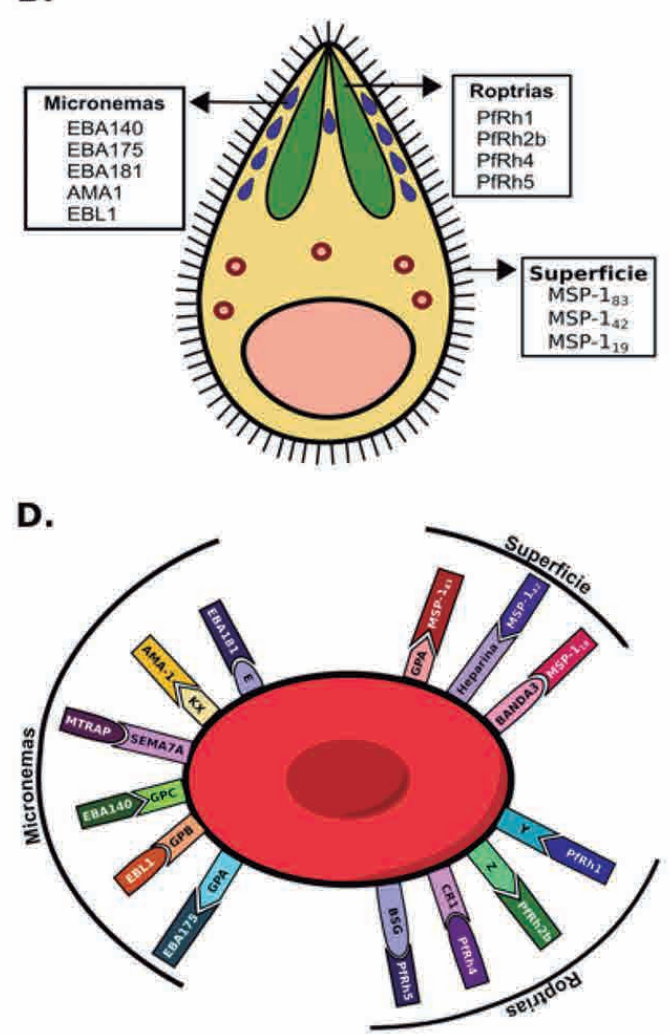

Fuente: autores 
El sitio de interacción receptor-ligando corresponde a un glucopéptido que contiene 16 sialotetrasacáridos unidos a $\mathrm{O}$ ( $\mathrm{MCH} 1$ aa1-64), sugiriendo que además de los residuos de ácido siálico, la presencia de ciertos aminoácidos de la GPA es imprescindible para la unión (28), convirtiéndolos en potenciales fragmentos para la inducción de anticuerpos contra mrz al bloquear específicamente la unión a GPA (29-33). Debido a la gran importancia de EBA-175 en la activación de los mrz y en la invasión para aumentar la respuesta inmune, se han enfocado múltiples esfuerzos en el desarrollo de vacunas contra la malaria que incluyan a esta proteína (34).

\section{Glicoforina B}

La GPB es estructuralmente similar a la GPA, con la excepción de la cola citoplasmática, la cual es mucho más corta en GPB; esta proteína está codificada por un gen separado para GPA que probablemente surgió por duplicación genética del gen GPA original (35).

La GPB está presente de $0.2-1.0 \times 10^{5}$ copias por GR $(22,35)$, tiene un peso molecular de $\sim 10 \mathrm{kDa}$ y comprende 91 residuos (22) (Figura 2B); junto a GPA, es la sialo-glicoproteína principal de membrana de eritrocitos y es el determinante antigénico para el grupo sanguíneo Ss (36).

En el año 2009, se descubrió que GPB media la entrada del parásito a través del ligando de unión a eritrocitos-1 (EBL-1), esta unión es sensible al tratamiento con neuraminidasa, indicando que el sitio de unión de EBL-1 incluye un epítope con ácido siálico en la superficie de GPB (37). Se ha reportado que el sitio de unión EBL-1/GPYB se encuentra localizado en la región F2i (residuos ${ }^{601} \mathrm{C}-\mathrm{V}^{669}$ ) (15).

A partir de ensayos de invasión, se ha propuesto un nivel de redundancia entre las proteínas EBA-175 y EBL-1 que se unen a estas glicoforinas similares, debido a que GRs negativos de GPB presen$\tan 40 \%-79 \%$ de resistencia a la invasión de $P$. falciparum y resistencia casi completa después de la eliminación de GPA del GR con tripsina. Así mismo, se ha planteado la hipótesis de que GPB pudo haber surgido como resultado de la presión selectiva para perder el sitio de unión de EBA-175 en GPA (38).

\section{Glicoforina C}

GPC es el tercer miembro de la familia de glicoforinas eritrocitarias. Esta proteína está presente en $1.35-1.43 \times 10^{5}$ copias por GR (35). Su estructura la conforman los dominios extracelular, transmembranal y citoplasmático, distribuidos en 128 residuos con 12 O-glicanos y un solo $\mathrm{N}$-glicano (Figura 2C) (39). Dicha glicoforina tiene una importante función en el mantenimiento de la forma de los GRs y en la regulación de los componentes de la membrana celular a través de la interacción con la proteína 4.1 (39). 
GPC es el receptor de GR para el antígeno de unión a eritrocito-140 (EBA-140) de $P$. falciparum. EBA-140 se une a los residuos 14-22 codificados por el exón 2 de GPC $(40,41)$, de una forma sensible al tratamiento con neuraminidasa y tripsina y resistente a quimiotripsina (11).

Sin embargo, la naturaleza del sitio de unión entre EBA-140 y GPC ha resultado difícil de precisar, puesto que la sensibilidad a la neuraminidasa indica una dependencia de ácido siálico para la unión, no obstante, esto ha sido cuestionado debido a la incapacidad de EBA-140 para unirse a los GRs que expresan la variante de supresión natural mal glicosilada de la GPC, denominada Gerbich (42).

Debido a esto, se ha considerado que EBA-140 presenta vías alternas de invasión, puesto que tiene polimorfismos capaces de invadir GRs tratados con neuraminidasa (43).

Estos datos sugieren que las proteínas de invasión de $P$. falciparum, tienen funciones redundantes, ya que EBA-140 no es esencial en el proceso de invasión del mrz al GR, siempre y cuando se asegure una interacción entre suficientes ligandos similares de invasión con receptores de la célula hospedera (44).

\section{Semaforina 7a}

Las semaforinas son proteínas secretadas y asociadas a la membrana del GR, caracterizadas por tener en el N-terminal un dominio extracelular conservado "Sema" (45). Se han descrito ocho clases de semaforinas, las cuales presentan similitudes en las secuencias de aminoácidos de sus miembros. De estas, las semaforinas 1 y 2 se encuentran en invertebrados, las clases 3-7 en vertebrados y la clase 8 en virus $(46,47)$.

Sema7a, también conocida como clúster de diferenciación 108 (CD108) o como antígeno de grupo sanguíneo John Milton Hagen (JMH), es una proteína de membrana glicosilada de 666 residuos y $75 \mathrm{kDa}$, asociada a las superficies celulares a través del dominio glicosilfosfatidil-inositol (GPI) (Figura 2D). Esta proteína se encuentra expresada en GR, neuronas pre y post natales, linfocitos y timocitos activados (33-35).

Las semaforinas fueron descritas inicialmente por su función en la guía axonal durante la neurogénesis (46); sin embargo, Sema7a también interviene en procesos moleculares y fisiológicos como la organogénesis, el crecimiento vascular, la regulación de las células inmunes al asociarse con integrinas y la producción de citoquinas inflamatorias como interleuquina-6 (IL-6), IL-8 y factor de necrosis tumoral (TNF) $(45,46,48,50)$. Así mismo, Sema7a es el receptor en los GR para 
la proteína anónima análoga a la repetición de trombospondina específica de mrz (MTRAP) de $P$. falciparum. Estas proteínas se asocian de forma dimérica con los dos monómeros de MTRAP que interactúan con cada homodímero a través de sus dominios Sema (Figura 3A) (51). Los polimorfismos en el dominio extracelular de Sema7a no afectan la unión a MTRAP, así mismo, en ensayos de invasión in vitro, se observó que la adición de anticuerpos contra Sema7a no inhibe la invasión del mrz al GR (52).

Se ha demostrado que Sema7a, tiene funciones importantes en las células inmunes al asociarse con integrinas, sin embargo, actualmente no se ha determinado el número de copias ni la función de esta proteína en los GRs, lo cual obstaculiza la especulación sobre la relevancia de sus propiedades en la célula hospedera al momento de la interacción con un ligando de invasión.

\section{KX}

AMA-1 se une al GR a través del dominio III, a un receptor putativo no identificado denominado $\mathrm{KX}$; esta unión es resistente al tratamiento enzimático con tripsina y neuraminidasa (53).

AMA-1 es un importante ligando de $P$. falciparum localizado en los micronemas; es una proteína procesada durante el desarrollo tardío del mrz y está involucrada en la formación de la unión estrecha que tiene lugar durante el proceso de invasión (54). Se divide en tres dominios (I,II y III) altamente conservados entre las especies de Plasmodium, sugiriendo una función importante en el proceso de invasión al GR $(54,55)$.

La identificación de un receptor de eritrocitos para un ligando crucial de la unión estrecha, proporcionaría un punto de partida útil en los esfuerzos por caracterizar las interacciones huésped-parásito en esta compleja estructura.

\section{W}

El antígeno de unión a ertrocito-181 (EBA-181), se une a un receptor en el GR hasta ahora no identificado, denominado W. Sin embargo, esta unión está caracterizada por su sensibilidad al tratamiento enzimático con neuraminidasa y quimiotripsina y su resistencia a la tripsina $(43,56)$. Así mismo, se ha documentado que EBA-181 se une a un fragmento de $10 \mathrm{kDa}$ de banda 4.1, con el mismo perfil de sensibilidad enzimática (57).

La remoción del gen de EBA-181 no presenta ninguna alteración en el proceso de invasión, lo cual sugiere que puede actuar como un ligando alternativo (58). 


\section{Receptores del hospedero que interactúan con proteínas de las roptrias de P. falciparum}

\section{Basigina}

BSG, también llamada clúster de diferenciación 147 (CD147) o inductor de metaloproteinasa de la matriz extracelular (EMMPRIN), es una glicoproteína transmembranal que pertenece a la superfamilia de las inmunoglobulinas (Ig), caracterizadas por tener al menos un dominio de lg (59). BSG es altamente glicosilada e incluye dos isoformas, basigina-1 (BSG-1) con tres dominios de Ig y dos sitios potenciales de N-glicosilación y basigina 2 (BSG-2) con dos dominios de lg y tres sitios potenciales de $\mathrm{N}$-glicosilación (59).

BSG-1 se ha identificado como la isoforma expresada en la retina (60) y BSG-2; por su parte, es la isoforma más común en diferentes tipos celulares, incluyendo células epiteliales, endoteliales y hematopoyéticas; además, es la variable presente en la superficie de los GRs $(59,61)$. BSG-2, tiene una longitud de 385 residuos y un peso molecular de 42-66 kDa que depende de su grado de $\mathrm{N}$-glicosilación. Está conformada por los dos dominios extracelulares de inmunoglobulina, una región transmembranal de 23 aminoácidos altamente conservados y una región citoplasmática (Figuras 2E y 3B) $(61,62)$.
Esta proteína está involucrada en diferentes funciones fisiológicas, incluyendo transporte de nutrientes, implantación embrionaria, espermatogénesis, desarrollo de retina, regulación de la respuesta de los linfocitos y expresión del transportador de monocilación (MCT) (59).

De acuerdo a su distribución, BSG-2 constituye el receptor para la proteína homologa de unión a reticulocitos de $P$. falciparum 5 (PfRH5) (63-65), el cual forma un complejo ternario con el antígeno protector rico en cisteína (CyRPA) y la proteína que interactúa con PfRh5 (Ripr) (66-68) que se posiciona de forma paralela a la membrana del GR. Después de unirse PfRh5 a BSG, el complejo se desensambla y CyRPA se excluye de la membrana, mientras que PfRh5 y Ripr se insertan en ella (68), permitiendo así la formación de un poro en la membrana del GR a través del cual entra $\mathrm{Ca}^{2+}$ a la célula (69).

Se ha determinado la importancia de la interacción PfRH5-BSG al inhibir PfRH5 con un anticuerpo IgG policlonal anti-PfRH5, encontrando una reducción de la invasión de $\sim 90 \%$ en la cepa 3D7 (70) y se han monitorizado múltiples rupturas de esquizontes en presencia de este anticuerpo policlonal sin obtener invasiones exitosas al GR (7). Así mismo, se ha demostrado que PfRH5 exhibe limitados polimorfismos y provoca potentes anticuerpos neutralizantes que inhiben la invasión del mrz, haciéndolo atractivo candidato a vacuna en etapa sanguínea (71). 
Y

Previo a la interacción de EBA-175 con el receptor de glicoforina A (GPYA), PfRh1 (considerado como uno de los primeros ligandos en interactuar), se une a un receptor en el GR a través de un fragmento de 333 aminoacidos (500-833) denominado RII-3, a un receptor putativo hasta ahora no caracterizado, denominado $Y$, el cual es resistente al tratamiento enzimático con tripsina y quimiotripsina y sensible a la neuraminidasa $(9,72)$.

\section{Z}

PfRH2b se sintetiza como una proteína de $\sim 380$ $\mathrm{kDa}$ siendo procesada en fragmentos de $\sim 300$, 250, 130 y $85 \mathrm{kDa}$ en las cepas W2-mef y 3D7, en donde junto con PfRH1, PfRH4 y PfRH5 están asociadas con la formación de la unión estrecha durante la invasión del mrz.

PfRH1 se une al GR a través del receptor putativo " $Z$ " a través de una interacción sensible al tratamiento con quimiotripsina y resistente a tripsina (73-75). La unión de PfRh2b a su receptor desencadena un flujo de $\mathrm{Ca}^{2+}$ en los mrz conduciendo a la liberación de EBA-175 de los micronemas (76).

\section{Receptor de complemento 1}

El CR1, es una proteína inmunorreguladora presente en la membrana de los GR y de los leucocitos; sus funciones incluyen la activación del sistema del complemento y la eliminación de complejos inmunes. Los niveles de expresión de CR1 están genéticamente determinados y están asociados con al menos tres polimorfismos de un solo nucleótido (SNP) en el gen CR1, variando en las diferentes poblaciones en un rango de $50-1.200$ moléculas por GR (77).

La proteína tiene un péptido señal de 47 residuos, un dominio extracelular de 1930 residuos, un dominio transmembranal de 25 residuos y una región citoplasmática C-terminal de 43 aminoácidos. El dominio extracelular tiene 25 sitios potenciales de $\mathrm{N}$-glicosilación y se puede dividir en 30 repeticiones de consenso corto (SCR), cada una de los cuales está conformada por $\sim 70$ residuos. Las 30 SCRs, a su vez, se pueden agrupar en 4 regiones más largas denominadas repeticiones homólogas largas (LHR): LHR-A, -B, -C y -D (Figuras 2F y 3C) (78).

CR1 ha sido identificado como receptor de la proteína homóloga de unión a reticulocitos de $P$. falciparum 4 (PfRh4) (79), siendo importante en las rutas de invasión independientes de ácido siálico al ser esta interacción resistente al tratamiento con neuraminidasa (80). Los residuos críticos en la unión en CR1 con PfRh4 son $\mathrm{D}^{18}$ y $\mathrm{F}^{20}$ localizados en el LHR-A (81). 


\section{Receptores que interactúan con proteínas de superficie de $P$. falciparum Banda 3 - MSP-1}

Banda 3, también llamada intercambiador de aniones (AE1) o portador de soluto familia 4 miembro 1 (SLC4A1), es la proteína más abundante $(25 \%)$ en la membrana de los GR $(82,83)$. Esta proteína tiene un papel fundamental en el suministro eficiente de oxígeno a los tejidos y en la eliminación de $\mathrm{CO}_{2}$, al facilitar el intercambio de cloruro y bicarbonato, desempeñando también funciones en la regulación del pH intracelular $(84,85)$.

Es una glicoproteína de 911 aminoácidos con un peso molecular de $110 \mathrm{kDa}$. Está constituida por dos dominios: un dominio $\mathrm{N}$-terminal citosólico (residuos 1-360) y un dominio integral de membrana con 8 hélices transmembranales (residuos 361 a 911) $(86,87)$ (Figura $2 \mathrm{G}$ y 3D). El dominio C-terminal cataliza el intercambio de aniones ( $\mathrm{Cl}^{-}$y $\left.\mathrm{HCO}^{-}\right)$a través de la membrana del GR para aumentar con esto su capacidad de transporte de $\mathrm{CO}_{2}$. Además, este dominio se asocia con la anhidrasa carbónica II, la cual juega un papel en el transporte del $\mathrm{CO}_{2}$ desde los tejidos hasta la circulación pulmonar (88). Por otro lado, el dominio $\mathrm{N}$-terminal citoplasmático es un importante sitio de anclaje para otras proteínas asociadas a membrana, tales como ankirina, desoxihemoglobina, proteína 4.1, proteína 4.2, gliceraldehído-3-fosfato deshidrogenasa, aldolasa, proteína tirosina quinasa y fosfofructoquinasa (83-85).

Banda 3, es un receptor esencial en las rutas de invasión independientes de ácido siálico para $P$. falciparum (89)MSP9, interactuando a través de la fuerte unión de dos regiones extracelulares no glicosiladas (residuos 720-761 y 807-826) con fragmentos de la proteína de superficie de merozoito-1 (MSP-1) MSP-1 ${ }_{42}$ y MSP-1 19 respectivamente (13).

MSP-1 es la proteína más abundante en la superficie del mrz (90); esta experimenta procesamiento proteolítico en el momento en que los mrz son liberados tras la ruptura del esquizonte generando cuatro fragmentos de 83, 30, 38 y 42 kDa, los cuales permanecen como un complejo multisubunitario en la superficie del mrz. A su vez, el fragmento de $42 \mathrm{kDa}$ se procesa y da como resultado los fragmentos de 33 y 19 kDa. La mayoría de estos fragmentos se desprende de la superficie del mrz durante el proceso de invasión, sin embargo, MSP-1 ${ }_{19}$ permanece unido (91).

Por otra parte, banda 3 está asociado con GPA, el receptor de EBA-175, a través de su octava hélice transmembranal por la presencia de Wrb, un antígeno de grupo sanguíneo (14). Esta asociación, puede aumentar la probabilidad de adhesión de los ligandos del parásito involucrados en el contacto con la célula hospedera. 
Figura 2. Esquema de la organización de dominios en receptores del eritrocito para proteínas de invasión de P. falciparum. A. Glicoforina A B. Glicoforina B C. Glicoforina C D. Semaforina 7a E. Basigina F. Receptor de complemento 1 G. Banda 3.

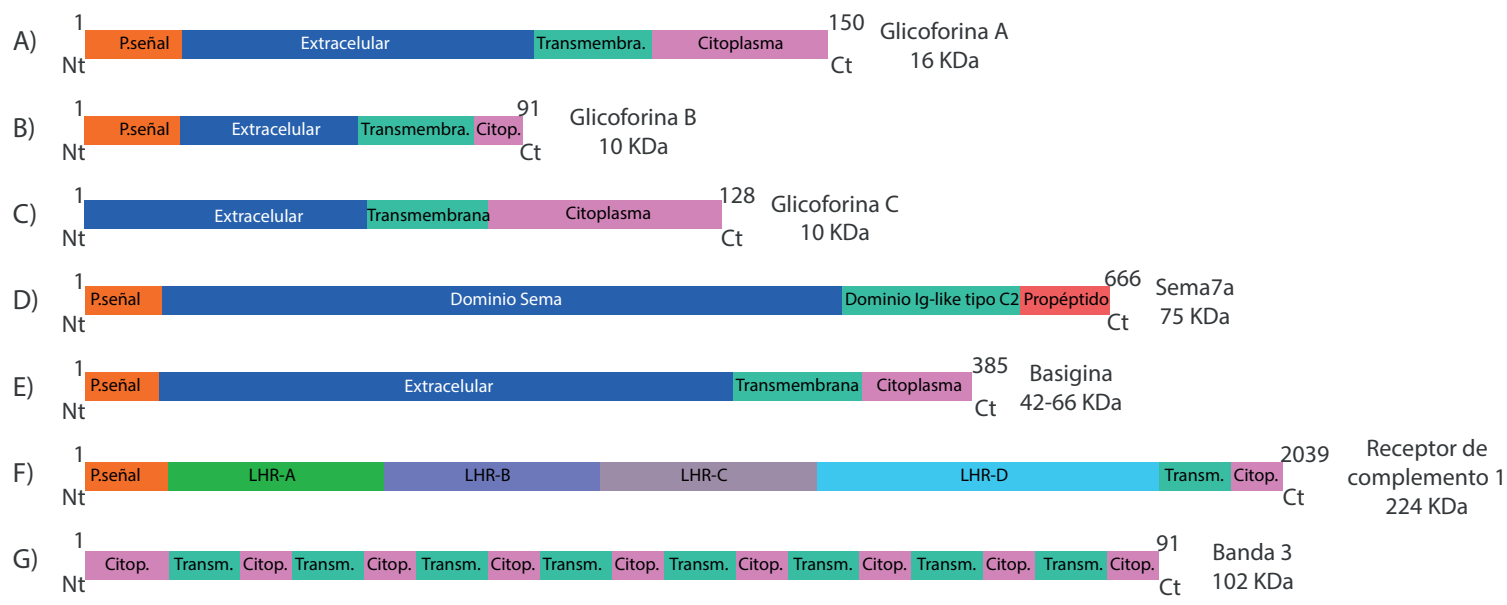

Figura 3. Estructura en cintas y en superficie de los receptores para P. falciparum A. Estructura dimérica de Sema7a PDB ID:3NVQ (40). B. Basigina PDB ID:4U0Q (54). C. CR1 PDB ID:2Q7Z (65). D. Banda 3 PDB ID:4YZF (84).

A)

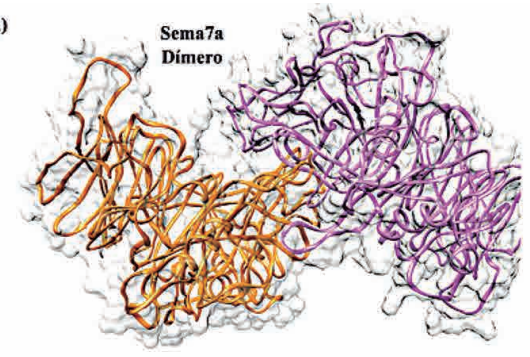

c)

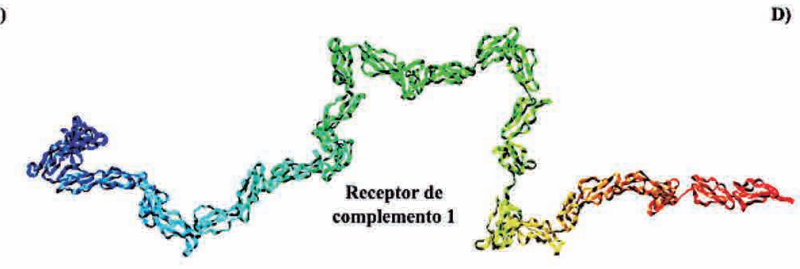

B)

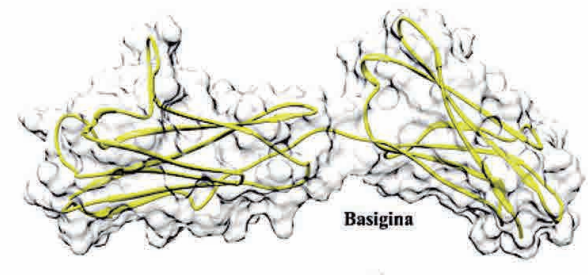

D)

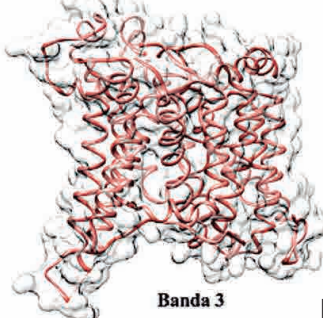

Fuente: autores

Volumen 6 • Número 2 • Julio - Diciembre 2019•ISSN 2389-7325・e-ISSN: 2539-2018 


\section{CONCLUSIÓN}

La malaria es la enfermedad parasitaria con mayor impacto mundial y representa un gran desafío para los servicios de salud pública. La forma de malaria más mortal es causada por $P$. falciparum, el cual cuenta con un amplio repertorio de proteínas de invasión expresadas por el mrz y que le permiten invadir a los GRs a través de uniones específicas y de alta afinidad.

El exitoso proceso de invasión de $P$. falciparum está determinado por funciones celulares, llevadas a cabo por proteínas (ligandos) que interactúan con los receptores del GR y forman complejos moleculares; la elucidación de estas interacciones es necesaria para lograr un profundo entendimiento de las bases biológicas y fisiológicas del parásito. A la fecha, se han descrito más de 50 ligandos del parásito y solo 9 receptores en el GR, evidenciando la existencia de una gran brecha en la identificación y caracterización de los receptores usados por Plasmodium en la célula hospedera.

En esta revisión se compilaron las características moleculares y estructurales de los receptores hasta ahora identificados; además, se resalta la importancia de la caracterización molecular de las diferentes rutas de invasión del mrz, lo cual ayudará a comprender la biología del parásito y servirá como base fundamental para poder desarrollar alternativas profilácticas o terapéuticas que conduzcan a mitigar o eliminar la malaria.

\section{CONFLICTOS DE INTERÉS}

Los autores declaran no tener conflictos de interés.

\section{FINANCIACIÓN}

Artículo realizado con financiación de la Universidad de Boyacá.

\section{REFERENCIAS}

1. World Health Organization. World malaria report 2018. 2018.

2. Howes RE, Battle $K E$, Mendis $K N$, Smith DL, Cibulskis RE, Baird JK, et al. Global Epidemiology of Plasmodium vivax. Am J Trop Med Hyg. 2016; 95(6Suppl):15-34. https://doi. org/10.4269/ajtmh.16-0141

3. Rodriguez LE, Curtidor H, Urquiza M, Cifuentes G, Reyes C, Patarroyo ME. Intimate Molecular Interactions of P. falciparum Merozoite Proteins Involved in Invasion of Red Blood Cells and Their Implications for Vaccine Design. Chem Rev. 2008;108(9):3656-705. https://doi. org/10.1021/cr068407v

4. Cowman AF, Tonkin CJ, Tham W-H, Duraisingh MT. The Molecular Basis of Erythrocyte Invasion by Malaria Parasites. Cell Host Microbe. 2017;22(2):232-45. https://doi.org/10.1016/j. chom.2017.07.003 
5. Baum J, Richard D, Riglar DT. Malaria Parasite Invasion: Achieving Superb Resolution. Cell Host Microbe. 2017;21(3):294-6. https://doi. org/10.1016/j.chom.2017.02.006

6. Weiss GE, Crabb BS, Gilson PR. Overlaying Molecular and Temporal Aspects of Malaria Parasite Invasion. Trends Parasitol. 2016;32(4):284-95. https://doi.org/10.1016/j.pt.2015.12.007

7. W Weiss GE, Gilson PR, Taechalertpaisarn T, Tham $\mathrm{W}-\mathrm{H}$, de Jong NWM, Harvey $\mathrm{KL}$, et al. Revealing the Sequence and Resulting Cellular Morphology of Receptor-Ligand Interactions during Plasmodium falciparum Invasion of Erythrocytes. PLOS Pathog. 2015;11(2):1-25. https://doi.org/10.1371/journal.ppat.1004670

8. Karunamoorthi K. Malaria vaccine: a future hope to curtail the global malaria burden. Int J Prev Med. 2014;5(5):529-38. PMCID:PMC4050672.

9. Beeson JG, Drew DR, Boyle MJ, Feng G, Fowkes FJI, Richards JS. Merozoite surface proteins in red blood cell invasion, immunity and vaccines against malaria. van Ooij $C$, editor. FEMS Microbiol Rev. 2016;40(3):343-72. https://doi. org/10.1093/femsre/fuw001

10. Gaur D, Mayer DCG, Miller LH. Parasite ligand-host receptor interactions during invasion of erythrocytes by Plasmodium merozoites. Int
J Parasitol. 2004;34(13-14):1413-29. https:// doi.org/10.1016/j.ijpara.2004.10.010

11. Pasvol G. How many pathways for invasion of the red blood cell by the malaria parasite? Trends Parasitol. 2003;19(10):430-2. https:// doi.org/10.1016/j.pt.2003.08.005

12. Kadekoppala M, Holder AA. Merozoite surface proteins of the malaria parasite: The MSP1 complex and the MSP7 family. Int J Parasitol. 2010;40(10):1155-61. https://doi.org/10.1016/j.ijpara.2010.04.008

13. Goel VK, Li X, Chen H, Liu S-C, Chishti AH, Oh SS. Band 3 is a host receptor binding merozoite surface protein 1 during the Plasmodium falciparum invasion of erythrocytes. Proc Natl Acad Sci. 2003;100(9):5164-9. https://doi. org/10.1073/pnas.0834959100

14. Baldwin MR, Li X, Hanada T, Liu S-C, Chishti AH. Merozoite surface protein 1 recognition of host glycophorin A mediates malaria parasite invasion of red blood cells. Blood. 2015;125(17):2704-11. https://doi.org/10.1182/blood-2014-11-611707

15. Li X, Marinkovic M, Russo C, McKnight CJ, Coetzer TL, Chishti AH. Identification of a specific region of Plasmodium falciparum EBL-1 that binds to host receptor glycophorin $B$ and inhibits merozoite invasion in 
human red blood cells. Mol Biochem Parasitol. 2012;183(1):23-31. https://doi.org/10.1016/j. molbiopara.2012.01.002

16. Rayner JC, Galinski MR, Ingravallo P, Barnwell JW. Two Plasmodium falciparum genes express merozoite proteins that are related to Plasmodium vivax and Plasmodium yoelii adhesive proteins involved in host cell selection and invasion. Proc Natl Acad Sci. 2000;97(17):964853. https://doi.org/10.1073/pnas.160469097

17. Lopaticki S, Maier AG, Thompson J, Wilson DW, Tham W-H, Triglia T, et al. Reticulocyte and Erythrocyte Binding-Like Proteins Function Cooperatively in Invasion of Human Erythrocytes by Malaria Parasites. Infect Immun. 2011;79(3):1107-17. https://doi.org/10.1128/IAl.01021-10

18. Gilson PR, Crabb BS. Morphology and kinetics of the three distinct phases of red blood cell invasion by Plasmodium falciparum merozoites. Int J Parasitol. 2009;39(1):91-6. https:// doi.org/10.1016/j.ijpara.2008.09.007

19. Cowman AF, Healer J, Marapana D, Marsh K. Malaria: Biology and Disease. Cell. octubre de 2016;167(3):610-24. https://doi.org/10.1016/j.cell.2016.07.055

20. Wahlgren M, Goel S, Akhouri RR. Variant surface antigens of Plasmodium falciparum and their roles in severe malaria. Nat Rev Microbiol. 2017;15(8):479-91. https://doi. org/10.1038/nrmicro.2017.47

21. Bermúdez M, Moreno-Pérez DA, Arévalo-Pinzón $\mathrm{G}$, Curtidor $\mathrm{H}$, Patarroyo MA. Plasmodium vivax in vitro continuous culture: the spoke in the wheel. Malar J. $2018 ; 17(1)$. https://doi. org/10.1186/s12936-018-2456-5

22. Aoki T. A Comprehensive Review of Our Current Understanding of Red Blood Cell (RBC) Glycoproteins. Membranes. 2017;7(4):56. https://doi.org/10.3390/membranes7040056

23. Tomita M, Marchesi VT. Amino-acid sequence and oligosaccharide attachment sites of human erythrocyte glycophorin. Proc Natl Acad Sci. 1975;72(8):2964-8. https://doi. org/10.1073/pnas.72.8.2964

24. Hassan SN, Thirumulu Ponnuraj K, Mohamad $S$, Hassan R, Wan Ab Rahman WS. Molecular Detection of Glycophorins A and B Variant Phenotypes and their Clinical Relevance. Transfus Med Rev. 2019;33(2):118-24. https:// doi.org/10.1016/j.tmrv.2019.02.003

25. Duraisingh MT, Maier AG, Triglia T, Cowman AF. Erythrocyte-binding antigen 175 mediates invasion in Plasmodium falciparum utilizing sialic acid-dependent and -independent pathways. 
Proc Natl Acad Sci. 2003;100(8):4796-801. https://doi.org/10.1073/pnas.0730883100.

26. Tolia NH, Enemark EJ, Sim BKL, Joshua-Tor L. Structural Basis for the EBA-175 Erythrocyte Invasion Pathway of the Malaria Parasite Plasmodium falciparum. Cell. 2005;122(2):18393. https://doi.org/10.1016/j.cell.2005.05.033

27. Wanaguru M, Crosnier $C$, Johnson S, Rayner JC, Wright GJ. Biochemical Analysis of the Plasmodium falciparum Erythrocyte-binding Antigen-175 (EBA175)-Glycophorin-A Interaction: implications for vaccine design. J Biol Chem. 2013;288(45):32106-17. https://doi. org/10.1074/jbc.M113.484840

28. Sim BKL, Chitnis CE, Wasniowska K, Millert LH. Receptor and ligand domains for invasion of erythrocytes by Plasmodium falciparum. 1994;264:4. https://doi.org/10.1126/science.8009226

29. Jaskiewicz E, Jodłowska M, Kaczmarek R, Zerka A. Erythrocyte glycophorins as receptors for Plasmodium merozoites. Parasit Vectors. 2019;12(1):317. https://doi.org/10.1186/s13071-019-3575-8

30. Narum DL, Haynes JD, Fuhrmann S, Moch K, Liang $\mathrm{H}$, Hoffman $\mathrm{SL}$, et al. Antibodies against the Plasmodium falciparum Receptor Binding Domain of EBA-175 Block Invasion Pathways That Do Not Involve Sialic Acids. Infect Immun.
2000;68(4):1964-6. https://doi.org/10.1128/ IAI.68.4.1964-1966.2000

31. Ohas EA, Adams JH, Waitumbi JN, Orago ASS, Barbosa A, Lanar DE, et al. Measurement of Antibody Levels against Region II of the Erythrocyte-Binding Antigen 175 of Plasmodium falciparum in an Area of Malaria Holoendemicity in Western Kenya. Infect Immun. 2004;72(2):735-41. https://doi.org/10.1128/ IAI.72.2.735-741.2004

32. El Sahly HM, Patel SM, Atmar RL, Lanford TA, Dube T, Thompson D, et al. Safety and Immunogenicity of a Recombinant Nonglycosylated Erythrocyte Binding Antigen 175 Region II Malaria Vaccine in Healthy Adults Living in an Area Where Malaria Is Not Endemic. Clin Vaccine Immunol. 2010;17(10):1552-9. https://doi.org/10.1128/CVI.00082-10

33. Koram KA, Adu B, Ocran J, Karikari YS, AduAmankwah S, Ntiri M, et al. Safety and Immunogenicity of EBA-175 RII-NG Malaria Vaccine Administered Intramuscularly in Semi-Immune Adults: A Phase 1, Double-Blinded Placebo Controlled Dosage Escalation Study. PLOS ONE. 2016;11(9):e0163066. https://doi. org/10.1371/journal.pone.0163066

34. Salamanca DR, Gómez M, Camargo A, Cuy-Chaparro L, Molina-Franky J, Reyes C, et al. 
Plasmodium falciparum Blood Stage Antimalarial Vaccines: An Analysis of Ongoing Clinical Trials and New Perspectives Related to Synthetic Vaccines. Front Microbiol. 2019;10:2712. https://doi.org/10.3389/fmicb.2019.02712

35. Satchwell TJ. Erythrocyte invasion receptors for Plasmodium falciparum: new and old: Erythrocyte invasion receptors for Plasmodium falciparum. Transfus Med. 2016;26(2):77-88. https://doi.org/10.1111/tme.12280

36. Willemetz A, Nataf J, Peyrard T, Arnaud L. A novel GYPB-A-B hybrid gene responsible for Ss and MN typing discrepancies. Transfusion. 2015;55(11):2620-3. https://doi.org/10.1111/ trf.13216

37. Mayer DCG, Cofie J, Jiang L, Hartl DL, Tracy $E$, Kabat J, et al. Glycophorin B is the erythrocyte receptor of Plasmodium falciparum erythrocyte-binding ligand, EBL-1. Proc Natl Acad Sci. 2009;106(13):5348-52. https://doi. org/10.1073/pnas.0900878106

38. Salinas ND, Paing MM, Tolia NH. Critical Glycosylated Residues in Exon Three of Erythrocyte Glycophorin A Engage Plasmodium falciparum EBA-175 and Define Receptor Specificity. mBio. 2014;5(5):e01606-14. https://doi. org/10.1128/mBio.01606-14
39. Reid ME, Takakuwa Y, Conboy J, Mohandas N. Glycophorin C content of human erythrocyte membrane is regulated by protein 4.1. Blood. 1990; 75(11)2229-34. PMID: 2346783.

40. Lobo C-A. Glycophorin C is the receptor for the Plasmodium falciparum erythrocyte binding ligand PfEBP-2 (baebl). Blood. 2003;101(11):462831. https://doi.org/10.1182/blood-2002-10-3076

41. Maier AG, Duraisingh MT, Reeder JC, Patel SS, Kazura JW, Zimmerman PA, et al. Plasmodium falciparum erythrocyte invasion through glycophorin $C$ and selection for Gerbich negativity in human populations. Nat Med. 2003;9(1):8792. https://doi.org/10.1038/nm807

42. Patel SS, King CL, Mgone CS, Kazura JW, Zimmerman PA. Glycophorin C (Gerbich antigen blood group) and band 3 polymorphisms in two malaria holoendemic regions of Papua New Guinea. Am J Hematol. 2004;75(1):1-5. https://doi.org/10.1002/ajh.10448

43. Maier AG, Baum J, Smith B, Conway DJ, Cowman AF. Polymorphisms in Erythrocyte Binding Antigens 140 and 181 Affect Function and Binding but Not Receptor Specificity in P11lasmodium falciparum. Infect Immun. 2009;77(4):1689-99. https://doi.org/10.1128/ IAI.01331-08 
44. Thompson JK, Triglia T, Reed MB, Cowman AF. A novel ligand from Plasmodium falciparum that binds to a sialic acid-containing receptor on the surface of human erythrocytes: A P. falciparum ligand that binds a sialylated receptor on erythrocytes. Mol Microbiol. 2001;41(1):47-58. https://doi.org/10.1046/ j.1365-2958.2001.02484.x

45. Kang S, Kumanogoh A. Semaphorins in bone development, homeostasis, and disease. Semin Cell Dev Biol. 2013;24(3):163-71. https://doi. org/10.1016/j.semcdb.2012.09.008

46. Xie J, Wang H. Semaphorin $7 \mathrm{~A}$ as a potential immune regulator and promising therapeutic target in rheumatoid arthritis. Arthritis Res Ther. 2017;19(1):10. https://doi.org/10.1186/ s13075-016-1217-5

47. Nogi T, Yasui N, Mihara E, Matsunaga $Y$, Noda $\mathrm{M}$, Yamashita $\mathrm{N}$, et al. Structural basis for semaphorin signalling through the plexin receptor. Nature. 2010;467(7319):1123-7. https:// doi.org/10.1038/nature09473

48. Czopik AK, Bynoe MS, Palm N, Raine CS, Medzhitov R. Semaphorin 7A Is a Negative Regulator of $\mathrm{T}$ Cell Responses. Immunity. 2006;24(5):591-600. https://doi.org/10.1016/j.immuni.2006.03.013
49. Jeroen Pasterkamp R, Peschon JJ, Spriggs MK, Kolodkin AL. Semaphorin 7A promotes axon outgrowth through integrins and MAPKs. Nature. 2003;424(6947):398-405. https://doi. org/10.1038/nature01790

50. Holmes $S$, Downs A-M, Fosberry $A$, Hayes $P D$, Michalovich $D$, Murdoch $P$, et al. Sema7A is a Potent Monocyte Stimulator. Scand J Immunol. 2002;56(3):270-5. https://doi.org/10.1046/j.1365-3083.2002.01129.x

51. Liu H, Juo ZS, Shim AH-R, Focia PJ, Chen X, Garcia KC, et al. Structural Basis of Semaphorin-Plexin Recognition and Viral Mimicry from Sema7A and A39R Complexes with PlexinC1. Cell. 2010;142(5):749-61. https://doi.org/10.1016/j.cell.2010.07.040

52. Bartholdson SJ, Bustamante LY, Crosnier C, Johnson S, Lea S, Rayner JC, et al. Semaphorin-7A Is an Erythrocyte Receptor for P. falciparum Merozoite-Specific TRAP Homolog, MTRAP. PLoS Pathog. 2012;8(11):1-13. https:// doi.org/10.1371/journal.ppat.1003031

53. Kato K, Mayer DCG, Singh S, Reid M, Miller LH. Domain III of Plasmodium falciparum apical membrane antigen 1 binds to the erythrocyte membrane protein Kx. Proc Natl Acad Sci. 2005;102(15):5552-7. https://doi. org/10.1073/pnas.0501594102 
54. Triglia T, Healer J, Caruana SR, Hodder AN, Anders RF, Crabb BS, et al. Apical membrane antigen 1 plays a central role in erythrocyte invasion by Plasmodium species. Mol Microbiol. 2000;38(4):706-18. https://doi.org/10.1046/ j.1365-2958.2000.02175.x

55. Hodder AN, Crewther PE, Matthew MLSM, Reid GE, Moritz RL, Simpson RJ, et al. The Disulfide Bond Structure of Plasmodium Apical Membrane Antigen-1. J Biol Chem. 1996;271 (46):2944652. https://doi.org/10.1074/jbc.271.46.29446

56. Gilberger T-W, Thompson JK, Reed MB, Good RT, Cowman AF. The cytoplasmic domain of the Plasmodium falciparum ligand EBA-175 is essential for invasion but not protein trafficking. J Cell Biol. 2003;162(2):317-27. https:// doi.org/10.1083/jcb.200301046

57. Lanzillotti R, Coetzer TL. The $10 \mathrm{kDa}$ domain of human erythrocyte protein 4.1 binds the Plasmodium falciparum EBA-181 protein. Malar J. 2006;5(1):100. https://doi.org/10.1186/14752875-5-100

58. Gilberger T-W, Thompson JK, Triglia T, Good RT, Duraisingh MT, Cowman AF. A Novel Erythrocyte Binding Antigen-175 Paralogue from Plasmodium falciparum Defines a New Trypsin-resistant Receptor on Human Erythrocytes. J Biol Chem. 2003;278(16):14480-6. https://doi.org/10.1074/jbc.M211446200
59. Muramatsu T. Basigin (CD147), a multifunctional transmembrane glycoprotein with various binding partners. J Biochem. 2016;159(5):48190. https://doi.org/10.1093/jb/mvv127

60. Ochrietor JD, Moroz TP, van Ekeris L, Clamp MF, Jefferson SC, deCarvalho AC, et al. Retina-Specific Expression of 5A11/Basigin-2, a Member of the Immunoglobulin Gene Superfamily. Investig Opthalmology Vis Sci. 2003;44(9):4086. https://doi.org/10.1167/iovs.02-0995

61. Yurchenko V, Constant S, Eisenmesser E, Bukrinsky M. Cyclophilin-CD147 interactions: a new target for anti-inflammatory therapeutics: CD147-cyclophilin interactions. Clin Exp Immunol. 2010;160(3):305-17. https://doi.org/10.1111/j.1365-2249.2010.04115.x

62. Heller M, von der Ohe M, Kleene R, Mohajeri $\mathrm{MH}$, Schachner $\mathrm{M}$. The immunoglobulin-superfamily molecule basigin is a binding protein for oligomannosidic carbohydrates: an anti-idiotypic approach: Basigin binds to oligomannosidic glycans. J Neurochem. 2003;84(3):557-65. https:// doi.org/10.1046/j.1471-4159.2003.01537.x

63. Rodriguez $M$, Lustigman $S$, Montero $E$, Oksov Y, Lobo CA. PfRH5: a novel reticulocyte-binding family homolog of plasmodium falciparum that binds to the erythrocyte, and an investigation of its receptor. PloS One. 2008;3(10):1-8. https://doi.org/10.1371/journal.pone.0003300 
64. Arévalo-Pinzón $G$, Curtidor $H$, Muñoz M, Patarroyo MA, Bermudez A, Patarroyo ME. A single amino acid change in the Plasmodium falciparum RH5 (PfRH5) human RBC binding sequence modifies its structure and determines species-specific binding activity. Vaccine. 2012;30(3):637-46. https://doi.org/10.1016/j.vaccine.2011.11.012

65. Wright KE, Hjerrild KA, Bartlett J, Douglas AD, Jin J, Brown RE, et al. Structure of malaria invasion protein $\mathrm{RH} 5$ with erythrocyte basigin and blocking antibodies. Nature. 2014;515(7527):42730. https://doi.org/10.1038/nature13715

66. Reddy KS, Amlabu E, Pandey AK, Mitra P, Chauhan VS, Gaur D. Multiprotein complex between the GPI-anchored CyRPA with PfRH5 and PfRipr is crucial for Plasmodium falciparum erythrocyte invasion. Proc Natl Acad Sci. 2015;112(4):117984. https://doi.org/10.1073/pnas.1415466112

67. Ntege EH, Arisue N, Ito $D$, Hasegawa T, Palacpac NMQ, Egwang TG, et al. Identification of Plasmodium falciparum reticulocyte binding protein homologue 5-interacting protein, PfRipr, as a highly conserved blood-stage malaria vaccine candidate. Vaccine. 2016;34(46):5612-22. https://doi.org/10.1016/j.vaccine.2016.09.028

68. Wong W, Huang R, Menant S, Hong C, Sandow $\mathrm{JJ}$, Birkinshaw RW, et al. Structure of Plasmodium falciparum Rh5-CyRPA-Ripr invasion complex. Nature. 2019;565(7737):118-21. https://doi.org/10.1038/s41586-018-0779-6

69. Volz JC, Yap A, Sisquella X, Thompson JK, Lim NTY, Whitehead LW, et al. Essential Role of the PfRh5/PfRipr/CyRPA Complex during Plasmodium falciparum Invasion of Erythrocytes. Cell Host Microbe. 2016;20(1):60-71. https://doi. org/10.1016/j.chom.2016.06.004

70. Bustamante LY, Bartholdson SJ, Crosnier C, Campos MG, Wanaguru M, Nguon C, et al. A full-length recombinant Plasmodium falciparum PfRH5 protein induces inhibitory antibodies that are effective across common PfRH5 genetic variants. Vaccine. 2013;31(2):373-9. https://doi.org/10.1016/j.vaccine.2012.10.106

71. Payne RO, Silk SE, Elias SC, Miura K, Diouf A, Galaway $F$, et al. Human vaccination against RH5 induces neutralizing antimalarial antibodies that inhibit RH5 invasion complex interactions. JCI Insight. 2017;2(21): e96381. https:// doi.org/10.1172/jci.insight.96381

72. Gao X, Yeo KP, Aw SS, Kuss C, lyer JK, Genesan $S$, et al. Antibodies Targeting the PfRH1 Binding Domain Inhibit Invasion of Plasmodium falciparum Merozoites. PLoS Pathog. 2008;4(7):1-15. https://doi.org/10.1371/ journal.ppat.1000104 
73. Duraisingh MT, Triglia T, Ralph SA, Rayner JC, Barnwell JW, McFadden Gl, et al. Phenotypic variation of Plasmodium falciparum merozoite proteins directs receptor targeting for invasion of human erythrocytes. EMBO J. 2003;22(5):104757. https://doi.org/10.1093/emboj/cdg096

74. Aniweh Y, Gao X, Gunalan K, Preiser PR. PfRH2b specific monoclonal antibodies inhibit merozoite invasion: PfRH2b involves in $\mathrm{Ca}$ $2+$ signalling during merozoite invasion. Mol Microbiol. 2016;102(3):386-404. https://doi. org/10.1111/mmi.13468

75. Sahar T, Reddy KS, Bharadwaj M, Pandey AK, Singh S, Chitnis CE, et al. Plasmodium falciparum Reticulocyte Binding-Like Homologue Protein 2 (PfRH2) Is a Key Adhesive Molecule Involved in Erythrocyte Invasion. PLoS ONE. 2011;6(2):1-10. https://doi.org/10.1371/journal.pone.0017102

76. Gao X, Gunalan K, Yap SSL, Preiser PR. Triggers of key calcium signals during erythrocyte invasion by Plasmodium falciparum. Nat Commun. 2013;4(1):1-11. https://doi. org/10.1038/ncomms3862

77. Cockburn IA, Mackinnon MJ, O'Donnell A, Allen SJ, Moulds JM, Baisor M, et al. A human complement receptor 1 polymorphism that reduces Plasmodium falciparum rosetting confers protection against severe malaria.
Proc Natl Acad Sci. 2004;101(1):272-7. https:// doi.org/10.1073/pnas.0305306101

78. Furtado PB, Huang CY, Ihyembe D, Hammond RA, Marsh HC, Perkins SJ. The Partly Folded Back Solution Structure Arrangement of the 30 SCR Domains in Human Complement Receptor Type 1 (CR1) Permits Access to its C3b and C4b Ligands. J Mol Biol. 2008;375(1):10218. https://doi.org/10.1016/j.jmb.2007.09.085

79. Tham W-H, Wilson DW, Lopaticki S, Schmidt CQ, Tetteh-Quarcoo PB, Barlow PN, et al. Complement receptor 1 is the host erythrocyte receptor for Plasmodium falciparum PfRh4 invasion ligand. Proc Natl Acad Sci. 2010;107(40):1732732. https://doi.org/10.1073/pnas.1008151107

80. Spadafora C, Awandare GA, Kopydlowski KM, Czege J, Moch JK, Finberg RW, et al. Complement Receptor 1 Is a Sialic Acid-Independent Erythrocyte Receptor of Plasmodium falciparum. PLoS Pathog. 2010;6(6):1-13. https://doi. org/10.1371/journal.ppat.1000968

81. Park HJ, Guariento M, Maciejewski M, Hauhart $\mathrm{R}$, Tham W-H, Cowman AF, et al. Using Mutagenesis and Structural Biology to Map the Binding Site for the Plasmodium falciparum Merozoite Protein PfRh4 on the Human Immune Adherence Receptor. J Biol Chem. 2014;289(1):450-63. https://doi.org/10.1074/jbc.M113.520346 
82. Pantaleo A, Giribaldi G, Mannu F, Arese P, Turrini F. Naturally occurring anti-band 3 antibodies and red blood cell removal under physiological and pathological conditions. Autoimmun Rev. 2008;7(6):45762. https://doi.org/10.1016/j.autrev.2008.03.017

83. Zhang D, Kiyatkin A, Bolin JT, Low PS. Crystallographic structure and functional interpretation of the cytoplasmic domain of erythrocyte membrane band 3. Blood. 2000;96(9):2925-33. PMID: 11049968

84. Arakawa T, Kobayashi-Yurugi T, Alguel Y, Iwanari $H$, Hatae H, Iwata M, et al. Crystal structure of the anion exchanger domain of human erythrocyte band 3. Science. 2015; 350(6261):680-4. https://doi.org/10.1126/science.aaa4335

85. Lewis IA, Campanella ME, Markley JL, Low PS. Role of band 3 in regulating metabolic flux of red blood cells. Proc Natl Acad Sci. 2009;106(44):1851520. https://doi.org/10.1073/pnas.0905999106

86. Tanner MJA, Martin PG, High S. The complete amino acid sequence of the human erythrocyte membrane anion-transport protein deduced from the cDNA sequence. Biochem J. 1988;256(3):70312. https://doi.org/10.1042/bj2560703

87. Lux SE, John KM, Kopito RR, Lodish HF. Cloning and characterization of band 3 , the human erythrocyte anion-exchange protein
(AE1). Proc Natl Acad Sci. 1989;86(23):9089-

93. https://doi.org/10.1073/pnas.86.23.9089

88. Baldwin M, Yamodo I, Ranjan R, Li X, Mines G, Marinkovic $M$, et al. Human erythrocyte band 3 functions as a receptor for the sialic acid-independent invasion of Plasmodium falciparum. Role of the RhopH3-MSP1 complex. Biochim Biophys Acta BBA - Mol Cell Res. 2014;1843(12):2855-70. https://doi.org/10.1016/j.bbamcr.2014.08.008

89. Kariuki MM, Li X, Yamodo I, Chishti AH, Oh SS. Two Plasmodium falciparum merozoite proteins binding to erythrocyte band 3 form a direct complex. Biochem Biophys Res Commun. 2005;338(4):1690-5. https://doi.org/10.1016/j. bbrc.2005.10.154

90. Holder AA, Freeman RR. The three major antigens on the surface of Plasmodium falciparum merozoites are derived from a single high molecular weight precursor. J Exp Med. 1984;160(2):624-9. https://doi.org/10.1084/jem.160.2.624

91. McBride JS, Heidrich H-G. Fragments of the polymorphic Mr 185000 glycoprotein from the surface of isolated Plasmodium falciparum merozoites form an antigenic complex. Mol Biochem Parasitol. 1987;23(1):71-84. https:// doi.org/10.1016/0166-6851(87)90189-7

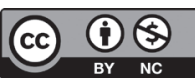

Esta obra está bajo una licencia de Creative Commons Reconocimiento-NoComercial 4.0 Internacional 